\title{
Long-term results of the Konno procedure for complex left ventricular oufflow tract obstruction
}

Rakesh M. Suri, MD, DPhil, Joseph A. Dearani, MD, Hartzell V. Schaff, MD, Gordon K. Danielson, MD, and Francisco J. Puga, MD

\section{GME Earn CME credits at http:// cme.ctsnetjournals.org}

Ð Supplemental material is available online.
From the Division of Cardiovascular Surgery, Mayo Clinic College of Medicine, Rochester, Minn.

Read at the Eighty-sixth Annual Meeting of The American Association for Thoracic Surgery, Philadelphia, Pa, April 29-May 3, 2006.

Received for publication May 9, 2006; revisions received June 16, 2006; accepted for publication July 7, 2006.

Address for reprints: Rakesh M. Suri, MD, DPhil, Division of Cardiovascular Surgery, Mayo Clinic College of Medicine, 200 First St SW, Rochester, MN 55905 (E-mail: suri. rakesh@mayo.edu).

J Thorac Cardiovasc Surg 2006;132:1064-71 $0022-5223 / \$ 32.00$

Copyright () 2006 by The American Association for Thoracic Surgery

doi:10.1016/j.jtcvs.2006.07.009
Objective: This study was undertaken to determine long-term clinical and echocardiographic outcomes after the Konno procedure.

Methods: Fifty-three patients who underwent the Konno procedure between January 1, 1980, and January 1, 2004, were reviewed.

Results: Mean age at operation was 19 years (range, 1-65 years). Indications were as follows: complex subaortic or tunnel stenosis in $22(41 \%)$, multilevel left ventricular outflow tract obstruction in $20(38 \%)$, and aortic valve stenosis or hypoplasia in $11(21 \%)$. Before the Konno procedure, 66 operations were performed in $41(77 \%)$ patients. Thirty-three (62\%) patients had greater than New York Heart Association class I symptoms preoperatively. A mechanical aortic valve was implanted in $40(75 \%)$, a homograft in $10(19 \%)$, and a xenograft prosthesis in $3(6 \%)$. Mortality at 30 days was $8 \%(n=4)$. Survival at 10 years was $86 \%$. Risk factors for overall mortality were New York Heart Association class (hazard ratio 2.22, $P=$ .04 ) and longer bypass time (hazard ratio 1.93 /hour, $P=.04$ ). The cumulative probability of aortic valve reoperation was $19 \%$ at 5 years and $39 \%$ at 10 years, occurring in 15 patients at a median of 3.8 years. The average left ventricular outflow tract mean gradients were $19 \mathrm{~mm} \mathrm{Hg}$ at 1 year $(\mathrm{n}=9), 13 \mathrm{~mm} \mathrm{Hg}$ at 1 to 3 years $(\mathrm{n}=9)$, and $13 \mathrm{~mm} \mathrm{Hg}$ at 3 to 5 years $(\mathrm{n}=5)$. Pulmonary regurgitation was detected in 6 patients. Pulmonary valve replacement was performed in $3(6 \%)$. At the date of last contact, all patients for whom data was available were in New York Heart Association functional class I or II.

Conclusion: The Konno procedure is effective, allowing both long-term reduction of left ventricular outflow tract obstruction and improvement in functional class. Prosthetic aortic valve and native pulmonary valve complications may necessitate reoperation.

$\mathrm{T}$ he surgical management of simple left ventricular outflow tract obstruction (LVOTO) confined to discrete subvalvular, ${ }^{1-8}$ valvular, ${ }^{9,10}$ or supravalvular ${ }^{11-14}$ levels has been well described in the literature. Complex LVOTO involving two or more levels of the outflow tract is a unique problem for which specific procedures have evolved. The aortoventriculoinfundibuloplasty (Konno procedure), described contemporaneously by both Konno and colleagues ${ }^{15}$ and Rastan and Koncz, ${ }^{16}$ was initially devised as an alternative to the apicoaortic conduit for the treatment of tunnel subaortic stenosis. The original description involved patch enlargement of both the left and right outflow tracts and the insertion of a mechanical aortic valve prosthesis. ${ }^{15,16}$ The Konno procedure has subsequently emerged as the procedure of multilevel LVOTO, particularly those with a small aortic annulus. ${ }^{17-22}$ The original technique of valve replacement has broadened recently to include biologic aortic prostheses. ${ }^{23-27}$

Although several studies have examined the midterm results of the Konno procedure, there are few data regarding the long-term results obtained for these 


\section{Abbreviations and Acronyms \\ LVOTO = left ventricular outflow tract obstruction \\ $\mathrm{PR} \quad=$ pulmonary regurgitation \\ PVR = pulmonary valve replacement}

patients. Moreover, the effects on left ventricular size and function after elimination of LVOTO remain unclear. The incision across the aortic annulus during the Konno procedure approaches both the conduction system and the native pulmonary valve. Although the risk of heart block has been documented in the literature, there is little information regarding native pulmonary valve function after this operation. The purpose of this study was to review the long-term results of the Konno procedure, including patient survival, reoperation risk, pulmonary valve complications, and effects on left ventricular size and function.

\section{Methods}

The records of 53 patients with complex LVOTO who underwent the Konno procedure at the Mayo Clinic Rochester between January 1, 1980, and January 1, 2004, were reviewed. The study was approved by the Mayo Clinic College of Medicine Institutional Review Board. Excluded from analysis were 5 other patients who underwent the Ross-Konno procedure. Three of those patients had a modified Konno procedure performed, involving septal patch enlargement of left ventricular outflow tract obstruction, before the standard Konno procedure. One patient underwent the first Konno procedure elsewhere and required a reoperative Konno procedure at our institution to correct recurrent stenosis at the valvular and subvalvular levels.

Demographic, morphologic, echocardiographic, and surgical data were obtained from hospital records, and a prospectively accrued SAS (SAS Institute, Inc, Cary, NC) database. There were 4 early ( $<30$ days or in-hospital) and 7 late deaths. Recent crosssectional follow-up was obtained through the Mayo Survey Research Center by means of telephone calls and written correspondence. Ten patients were unavailable for follow-up or refused further questionnaires; their last observed episodes were used for calculation purposes. The mean $( \pm \mathrm{SD})$ duration of follow-up for early survivors was $8.2 \pm 5.7$ years (range 14 days-22 years). There are currently 42 patients still alive, and current follow-up was available for 32 of them.

Echocardiographic data were obtained from the medical records and through contact with outside physicians. All gradients are reported as means and measured in millimeters of mercury. Ejection fraction and left ventricular end-diastolic and end-systolic dimensions were recorded as available.

\section{Statistical Analysis}

Survival and reoperation probabilities and $95 \%$ confidence intervals were computed with the Kaplan-Meier method (actuarial). The prognostic significances of potential risk factors were tested with the Cox proportional hazards models.
TABLE 1. Baseline characteristics

\begin{tabular}{|c|c|}
\hline Age (y, mean with range) & $19(1-65)$ \\
\hline \multicolumn{2}{|l|}{ Age (No.) } \\
\hline$<1 \mathrm{y}$ & 0 \\
\hline $1-10$ & $20(38 \%)$ \\
\hline$>10$ & $33(62 \%)$ \\
\hline \multicolumn{2}{|l|}{ Sex (No.) } \\
\hline Male & $27(51 \%)$ \\
\hline Female & $26(49 \%)$ \\
\hline \multicolumn{2}{|l|}{ Rhythm (No.) } \\
\hline Sinus & $52(98 \%)$ \\
\hline Paced & $1(2 \%)$ \\
\hline \multicolumn{2}{|l|}{ NYHA functional class (No.) } \\
\hline I & $20(38 \%)$ \\
\hline II & $30(57 \%)$ \\
\hline III & $2(4 \%)$ \\
\hline IV & $1(2 \%)$ \\
\hline \multicolumn{2}{|l|}{ Preoperative echocardiography } \\
\hline $\begin{array}{r}\text { Mean aortic gradient }(\mathrm{mm} \mathrm{Hg} \text {, } \\
\text { mean with range, } \mathrm{n}=25)\end{array}$ & $51(12-87)$ \\
\hline $\begin{array}{l}\text { Ejection fraction (\%, mean with range, } \\
n=50)\end{array}$ & $66 \%(15 \%-89 \%)$ \\
\hline LVEDD $(\%$, mean with range, $\mathrm{n}=40)$ & $44 \%(18 \%-92 \%)$ \\
\hline LVESD $(\%$, mean with range, $\mathrm{n}=40)$ & $25 \%(6 \%-84 \%)$ \\
\hline \multicolumn{2}{|l|}{ Regurgitation (No., $\mathrm{n}=41$ ) } \\
\hline $0-1$ & $6(15 \%)$ \\
\hline 2 & $7(17 \%)$ \\
\hline 3 & $14(34 \%)$ \\
\hline 4 & $14(34 \%)$ \\
\hline Operation before 1990 (No.) & $37(70 \%)$ \\
\hline
\end{tabular}

NYHA, New York Heart Association; LVEDD, left ventricular end-diastolic dimension; $L V E S D$, left ventricular end-systolic dimension.

\section{Results}

Baseline characteristics for the 53 patients included in the study are summarized in Table 1 . The age range at operation was 1 to 65 years. Most patients were in normal sinus rhythm before the operation, had minimal symptoms, and underwent operation after 1990. Before the Konno procedure, 41 patients had undergone 70 previous cardiovascular interventions (Table 2). Twenty-two patients (42\%) had a second operation before the Konno procedure, and 7 (13\%) had a third. Indications for the Konno procedure are described in Table E1. The most frequent reason for operation was to correct multilevel LVOTO $(\mathrm{n}=23,43 \%)$, followed by complex subaortic tunnel stenosis $(\mathrm{n}=18,34 \%)$ and valvular anomalies with annular hypoplasia ( $\mathrm{n}=12,23 \%)$.

The technical aspects of the Konno procedure are summarized in Table E2. As described in the classic description of the procedure, ${ }^{15}$ a mechanical valve was inserted in most cases $(n=40,75 \%)$. This was followed in frequency by a homograft ( $\mathrm{n}=10,19 \%)$ and, finally, a xenograft prosthesis $(\mathrm{n}=3,6 \%)$. The septal patch was constructed most frequently with untreated Dacron polyester fabric $(\mathrm{n}=30$, 
TABLE 2. Previous cardiovascular operations

\begin{tabular}{lccc}
\hline Operation & First & Second & Third \\
\hline Resection subaortic ridge & $10(19 \%)$ & $3(6 \%)$ & $3(6 \%)$ \\
Valvotomy & $9(17 \%)$ & $3(6 \%)$ & \\
Coarctation repair & $6(11 \%)$ & & \\
AVR & $4(8 \%)$ & $3(6 \%)$ & $2(4 \%)$ \\
Myectomy & $3(6 \%)$ & & \\
PAVC & $3(6 \%)$ & & \\
IAA & $2(4 \%)$ & & \\
CAVC & $1(2 \%)$ & $1(2 \%)$ & \\
PA band & $1(2 \%)$ & & \\
Aortic repair & $1(2 \%)$ & & \\
Ross procedure & $1(2 \%)$ & & \\
MVR & & $3(6 \%)$ & \\
Modified Konno & & $3(6 \%)$ & \\
Apicoaortic conduit & & $2(4 \%)$ & \\
Aortic root replacement & & $1(2 \%)$ & \\
PDA ligation & $1(2 \%)$ & \\
MV repair & $1(2 \%)$ & \\
VSD closure & & $1(2 \%)$ & \\
Konno procedure & & \\
Pericardiectomy & & & \\
\hline
\end{tabular}

Data are numbers and percentages of patients. $A V R$, aortic valve replacement; $P A V C$, partial anomalous venous connection; $C A V C$, complete atrioventricular canal defect; $\mathrm{PA}$, pulmonary artery; $I A A$, interrupted aortic arch; MVR, mitral valve replacement; Modified Konno, patch enlargement subarterial septum; $P D A$, patent ductus arteriosus; $M V$, mitral valve; $V S D$, ventricular septal defect.

57\%), whereas the remaining patients had pericardium, Meadox (Meadox Medicals, Oakland, NJ), Tascon (Tascon Industries, Houston, Tex), homograft, or polytetrafluoroethylene (Gore-Tex; W. L. Gore \& Associates, Inc, Flagstaff, Ariz). The right ventricular outflow tract reconstruction was most often performed with a bovine or autologous pericardial patch $(n=39,74 \%)$, and care was taken to avoid damaging the pulmonary valve. Concomitant procedures included mitral valve replacement $(\mathrm{n}=4,8 \%)$, mitral valve repair $(\mathrm{n}=3,6 \%)$, tricuspid valve repair $(\mathrm{n}=$ $2,4 \%)$, ventricular septal defect closure $(\mathrm{n}=2,4 \%)$, coronary artery bypass grafting $(\mathrm{n}=2,4 \%)$, and permanent pacemaker insertion $(\mathrm{n}=1,2 \%)$. Median bypass time was 173 minutes, and median crossclamp time was 114 minutes. Nonfatal complications included complete heart block requiring placement of a permanent pacemaker in 6 patients $(11 \%)$, sepsis in $2(4 \%)$, and bleeding, respiratory failure, and renal failure in 1 patient each.

Actuarial survival is shown in Figure 1. Early mortality was $8 \%(\mathrm{n}=4)$, whereas 5 - and 10-year survivals were $67 \%$ and $86 \%$, respectively. Univariate analysis of risk factors for mortality revealed only preoperative New York Heart Association functional class (hazard ratio 2.22, $P=$ .04 ) and longer bypass times (hazard ratio $1.93 / \mathrm{h}, P=.04$ )

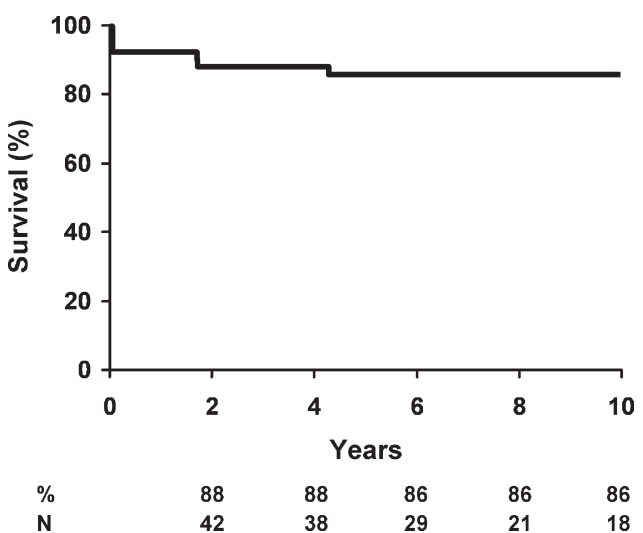

Figure 1. Kaplan-Meier freedom from death after Konno procedure versus time. Zero time on abscissa represents date of operation. Numbers at bottom of figure denote actuarial survivals (\%) and numbers of patients at risk $(\mathrm{N})$ at 2-year intervals.

as predictive (Table 3 ). The number of events was insufficient for multivariate modeling.

Sixteen aortic reoperations were performed in 15 patients, at a mean $( \pm \mathrm{SD})$ of 5 years \pm 4.4 after the Konno

TABLE 3. Univariate predictors of mortality

\begin{tabular}{|c|c|c|}
\hline Variable & $\begin{array}{c}\text { Hazard } \\
\text { ratio }\end{array}$ & $P$ value \\
\hline Age & 1.00 & .86 \\
\hline Female sex & 1.46 & .53 \\
\hline BSA & 1.92 & .32 \\
\hline NYHA functional class & 2.22 & .04 \\
\hline \multicolumn{3}{|l|}{ Indication for Konno } \\
\hline Tunnel subaortic & 0.81 & .76 \\
\hline Multilevel & 3.11 & .08 \\
\hline AS, AR, annular hypoplasia & 0.21 & .14 \\
\hline Preoperative AR ( $\mathrm{n}=41$ ) & 0.75 & .42 \\
\hline Preoperative AS, mean gradient $(n=25)$ & 1.02 & .51 \\
\hline Preoperative ejection fraction $(n=50)$ & 0.97 & .19 \\
\hline Preoperative LVEDD ( $\mathrm{n}=40$ ) & 0.95 & .35 \\
\hline Preoperative LVESD ( $\mathrm{n}=40$ ) & 1.03 & .36 \\
\hline Bypass & $1.93 / \mathrm{h}$ & .04 \\
\hline Crossclamp & 1.01 & .51 \\
\hline Operation 1990 or later vs before 1990 & 0.51 & .28 \\
\hline \multicolumn{3}{|l|}{ Valve type } \\
\hline Xenograft & NA & NA \\
\hline Mechanical & 1.37 & .69 \\
\hline Homograft & 0.92 & .91 \\
\hline Valve size & 1.08 & .45 \\
\hline Other previous operation & 1.17 & .84 \\
\hline Other concurrent operation & 1.35 & .66 \\
\hline
\end{tabular}

$B S A$, Body surface area; NYHA, New York Heart Association; $A S$, aortic stenosis; $A R$, aortic regurgitation; $\angle V E D D$, left ventricular end-diastolic dimension; $L V E S D$, left ventricular end-systolic dimension; $N A$, not applicable. 


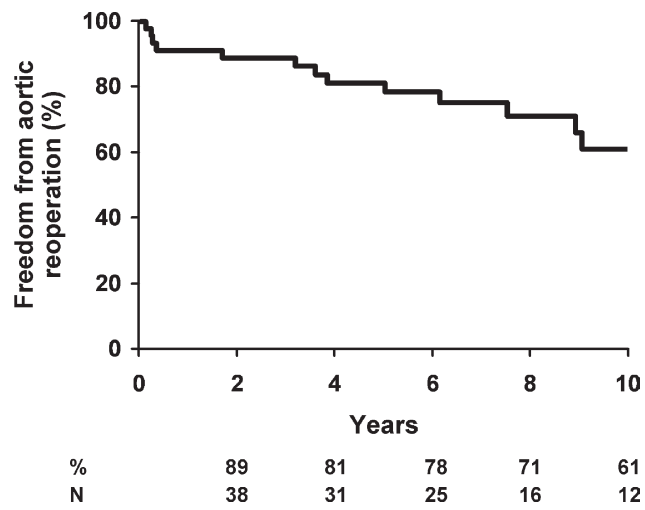

Figure 2. Kaplan-Meier freedom from aortic valve reoperation after Konno procedure versus time. Zero time on abscissa represents date of operation. Numbers at bottom of figure denote freedoms from aortic valve reoperation (\%) and numbers of patients at risk $(N)$ at 2-year intervals.

procedure (Figure 2). Of these, 11 patients had a mechanical valve, 3 had homografts, and 1 had a xenograft bioprosthesis. Indications for aortic reoperation (Table E3) included valve stenosis $(\mathrm{n}=6,11 \%)$, regurgitation $(\mathrm{n}=5,9 \%)$, and endocarditis $(n=3,6 \%)$. A larger prosthesis was placed at reoperation in all but 1 patient, in whom the cause of stenosis was subprosthetic pannus. No patients undergoing the Konno procedure at our institution required reoperation for recurrent subvalvular obstruction. The hazard phase for aortic reoperation was relatively constant after the Konno procedure, with 5- and 10-year survivals free of reoperation of $81 \%$ and $61 \%$, respectively. The linearized risk of aortic reoperation was 3.9\%/y. Among the 6 patients requiring reoperation for aortic valve stenosis, a mechanical prosthesis had been placed during the Konno procedure in 4, a homograft in 1, and a xenograft in 1 . In all cases but 1 , a larger size prosthesis was implanted at reoperation.

Causes of nonaortic reoperation were as follows: closure of a residual ventricular septal defect $(\mathrm{n}=3,6 \%)$, pulmonary valve replacement (PVR, $\mathrm{n}=3,6 \%)$, mitral valve replacement $(\mathrm{n}=2,4 \%)$, tricuspid valve replacement $(\mathrm{n}=$ $2,4 \%)$, and heart transplantation $(\mathrm{n}=1,2 \%)$. The only univariate factor predictive of a decreased risk for aortic reoperation was correction of tunnel subaortic stenosis (Table 4). In contrast, an operative indication of annular hypoplasia in conjunction with valvular stenosis or regurgitation was a risk factor for reoperation. The number of events was insufficient for construction of a multivariate model.

The presence of echocardiographically documented pulmonary regurgitation (PR) was found in 6 patients $(\mathrm{n}=5$ severe and $\mathrm{n}=1$ mild-moderate). PVR was performed in 3 patients at a mean $( \pm \mathrm{SD})$ of $2.1 \pm 3.5$ years after the Konno
TABLE 4. Univariate predictors of aortic valve reoperation

\begin{tabular}{lcc}
\hline Variable & $\begin{array}{c}\text { Hazard } \\
\text { ratio }\end{array}$ & $\boldsymbol{P}$ value \\
\hline Age & 0.97 & .13 \\
Female sex & 0.67 & .46 \\
BSA & 0.45 & .17 \\
NYHA functional class & 0.60 & .29 \\
Indication for Konno & & \\
$\quad$ Tunnel subaortic & 0.11 & .03 \\
$\quad$ Multilevel & 0.97 & .95 \\
$\quad$ AS, AR, annular hypoplasia & 4.55 & .004 \\
Preoperative AR (n = 41) & 0.77 & .34 \\
Preoperative AS, mean gradient (n $=25)$ & 0.99 & .6 \\
Preoperative ejection fraction (n $=50)$ & 1.02 & .65 \\
Preoperative LVEDD (n $=40)$ & 1.01 & .81 \\
Preoperative LVESD (n = 40) & 1.04 & .48 \\
Operation 1990 or later vs before 1990 & 2.16 & .25 \\
Valve type & & \\
$\quad$ Xenograft & 1.24 & .84 \\
$\quad$ Mechanical & 0.82 & .74 \\
$\quad$ Homograft & 1.17 & .81 \\
Valve size & 0.87 & .15 \\
Other previous operation & 1.46 & .62 \\
Other concurrent operation & 0.73 & .63 \\
\hline BSA, Body suce ar & & \\
\hline
\end{tabular}

$B S A$, Body surface area; NYHA, New York Heart Association; $A S$, aortic stenosis; $A R$, aortic regurgitation; $L V E D D$, left ventricular end-diastolic dimension; $L V E S D$, left ventricular end-systolic dimension.

procedure. The actuarial freedom from pulmonary complications (PR or PVR) is shown in Figure 3, demonstrating a hazard phase beginning early after the Konno procedure and continuing with time. The cumulative incidence of pulmonary complications at 10 years was $16 \%$.

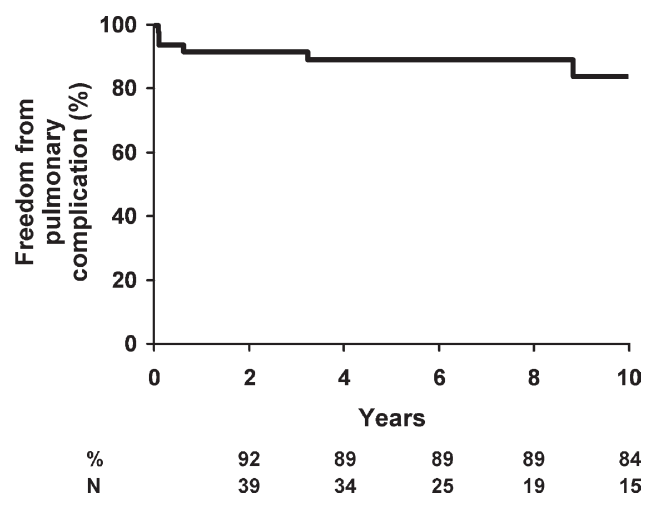

Figure 3. Kaplan-Meier freedom from pulmonary valve complications (pulmonary regurgitation or pulmonary valve replacement) after Konno procedure versus time. Zero time on abscissa represents date of operation. Numbers at bottom of figure denote freedoms from pulmonary valve complications (\%) and numbers of patients at risk $(\mathrm{N})$ at 2-year intervals. 
TABLE 5. Echocardiographic follow-up

\begin{tabular}{lccccc}
\hline Variable & Preoperative & Before DC & $<\mathbf{1}$ y & $\mathbf{1 - 3}$ y & $\mathbf{3 - 5}$ y \\
\hline $\begin{array}{l}\text { Mean gradient } \\
\text { (mm Hg) }\end{array}$ & $51(25)$ & $14(30)$ & $17(7)$ & $14(7)$ & $13(5)$ \\
$\begin{array}{l}\text { Ejection } \\
\text { fraction (\%) }\end{array}$ & $66(50)$ & $60(37)$ & $64(9)$ & $65(9)$ & $59(5)$ \\
LVEDD (\%) & $44(40)$ & $43(29)$ & $44(9)$ & $51(9)$ & $48(3)$ \\
LVESD (\%) & $25(40)$ & $27(29)$ & $27(9)$ & $27(9)$ & $34(2)$
\end{tabular}

Values are means; numbers in parentheses represent numbers of subjects. $\angle V E D D$, Left ventricular end-diastolic dimension; $L V E S D$, left ventricular end-systolic dimension.

Among patients who were still alive and for whom data were available at the date of last follow-up $(n=27)$, all were reported to be in New York Heart Association functional class I or II, and none had moderate or severe symptoms (functional class III or IV). Echocardiographic follow-up is presented in Table 5. The Konno procedure successfully diminished mean transaortic gradient from 51 $\mathrm{mm} \mathrm{Hg}$ preoperatively to $14 \mathrm{~mm} \mathrm{Hg}$ after surgery, the effect of which persisted during long-term follow-up.

\section{Discussion}

The proposed utility of the Konno procedure for the correction of complex LVOTO is well documented in the literature. ${ }^{17,21,24,28-30}$ Our study demonstrates that the procedure is associated with a significant decline in LVOTO gradient, stabilization of left ventricular function, and improvement in functional class. Predictors of mortality included greater preoperative symptoms and longer bypass time. The linearized aortic reoperation rate was significant, 3.9\% per year, and was increased among those in whom the procedure was used to correct aortic valve pathology in conjunction with annular hypoplasia. PR leading to reoperation was an important complication after the Konno procedure, one that is also seen in those undergoing the Ross-Konno procedure. ${ }^{31}$

The patients in our series had mild symptoms before the operation, most often mixed aortic regurgitation and aortic stenosis, as has been shown in other reports. ${ }^{21,24}$ Most patients $(79 \%)$ had previous interventions, and a significant number also had second (42\%) and third (13\%) operations before the Konno procedure, illustrating how difficult these patients are to manage with traditional palliative techniques aimed at relieving discrete or single-level obstruction. Similar combinations of complex left-sided obstruction treated by the Konno procedure have been reported elsewhere. ${ }^{19,21,24,32}$ The range and frequency of most perioperative nonfatal complications, including an $11 \%$ incidence of permanent heart block, parallel the results of others. ${ }^{17,19,28}$ Operative mortality in our study was $8 \%$ and long-term survival at 10 years was $86 \%$, again comparable to results reported elsewhere. ${ }^{17,19,28}$
Most of the patients in our series preferentially had a mechanical aortic valve prosthesis placed, consistent with the original description of the operation. ${ }^{15}$ We excluded from this study those patients who underwent the RossKonno procedure to examine the risk to the native pulmonary valve. Those who have popularized the use of the Ross-Konno procedure have suggested that the durability of autografts plus homografts is superior to other prostheses. ${ }^{24}$ A comparable duration of follow-up will be necessary to prove this point. Although we used aortic homografts for some patients in this study, the technical challenges associated with reoperation for homograft failure warrants that they be used with caution. ${ }^{33}$ The severe calcification seen in senescent homografts is perilous both at the time of reentry and during mobilization of coronary ostia.

The hazard phase for aortic reoperation (Figure 2) after the Konno procedure was relatively constant $(3.9 \%$ per year) and is somewhat disappointing, considering that it is a procedure designed to offer definitive correction of complex LVOTO. The reoperative risk associated with mechanical prostheses is related to complications of anticoagulation and thrombosis, endocarditis, and prosthesis obstruction by pannus. In contrast, the pattern of failure associated with bioprostheses is more likely related to structural deterioration. ${ }^{21,24}$ The durability of implanted homografts and xenografts has been surprising; as the duration since implantation lengthens, however, it is logical to expect a late hazard phase to become apparent. The low numbers of xenografts implanted in this series may partially explain why they did not surface as a risk factor.

Of the 6 patients requiring reoperation for aortic valve stenosis after the Konno procedure, 5 had a larger prosthesis placed. This leads us to suspect that the evolution of patientprosthetic mismatch with somatic growth was an important factor. In infants and small children, the Ross-Konno procedure may be the preferred choice. In others, careful attention may need to be given to maximizing prosthesis effective orifice area according to patient size. Increasing aortic prosthesis dimension, however, poses a further risk of compromise of the native pulmonary annulus. This issue will be studied further.

Echocardiographic follow-up demonstrated that after an initial postoperative decline, ejection fraction stabilized with time after the Konno procedure. Although it was initially suggested in the literature that biventricular incisions might adversely impact postoperative cardiac function, a recent report by Sharma and associates ${ }^{32}$ demonstrated that the recovery of ventricular function after the Konno procedure is analogous to that seen after aortic valve replacement alone. We are cognizant of the fact that the values observed at the last follow-up were probably affected by the small numbers of patients available for study. 
Our study has identified a nontrivial risk of pulmonary complications after the Konno procedure. This is represented by a hazard phase beginning immediately after operation and continuing with time. One other study reported the need for PVR in a patient 5 years after the Konno procedure for mixed PV stenosis and insufficiency. ${ }^{28}$ It has been noted elsewhere that opening the right ventricular outflow tract before incising the aortic annulus during the Konno procedure is important to protect both the native pulmonary valve and the conduction tissue. ${ }^{19}$ This is the practice at our institution. Despite these measures, 6 patients in our series had PR documented on follow-up echocardiography, and 3 required reoperation for PVR. The development of PR may be related to an initial injury to the pulmonary valve, disruption of the muscular subpulmonary conus, or distortion of the pulmonary annulus by the right ventricular patch. It is further possible that chronic elevation of left-sided pressures before the Konno procedure may predispose a damaged or weakened pulmonary valve toward progressive deterioration with time. The ability of younger patients to tolerate right-sided semilunar valve regurgitation in the absence of significant left-sided obstruction may subsequently contribute to delayed recognition. We suggest that the sequela of PR can be avoided by accurate incisions and symmetric reconstruction of the septum at the time of initial operation.

\section{Clinical Implications}

The Konno procedure is often considered as a final available option after initial attempts with "less invasive" catheter-based or surgical techniques fail to relieve complex LVOTO. Our data suggest that the Konno procedure should be used earlier in patients with less symptomatic disease, especially those in whom an expeditious procedure can be carried out to relieve aortic valve pathology in conjunction with tunnel subaortic obstruction. Clinical and echocardiographic surveillance after surgery is important to detect aortic and pulmonary valve complications during long-term follow-up.

\section{Conclusion}

The Konno procedure effectively relieves complex LVOTO, resulting in preservation of left ventricular ejection fraction and functional class. The linearized rate of aortic reoperation is $3.9 \%$ per year, which is higher than expected. The significant risk of pulmonary valve complications requires ongoing surveillance and perhaps technical modifications to protect the pulmonary valve complex from injury.

\section{References}

1. van Son JA, Schaff HV, Danielson GK, Hagler DJ, Puga FJ. Surgical treatment of discrete and tunnel subaortic stenosis. Late survival and risk of reoperation. Circulation. 1993;88(5 Pt 2):II159-69.
2. Reis RL, Hannah H 3rd, Carley JE, Pugh DM. Surgical treatment of idiopathic hypertrophic subaortic stenosis (IHSS). Postoperative results in 30 patients following ventricular septal myotomy and myectomy (Morrow procedure). Circulation. 1977;56(3 Suppl):II128-32.

3. McCully RB, Nishimura RA, Tajik AJ, Schaff HV, Danielson GK. Extent of clinical improvement after surgical treatment of hypertrophic obstructive cardiomyopathy. Circulation. 1996;94:467-71.

4. Theodoro DA, Danielson GK, Feldt RH, Anderson BJ. Hypertrophic obstructive cardiomyopathy in pediatric patients: results of surgical treatment. J Thorac Cardiovasc Surg. 1996;112:1589-99.

5. Minakata K, Dearani JA, Nishimura RA, Maron BJ, Danielson GK. Extended septal myectomy for hypertrophic obstructive cardiomyopathy with anomalous mitral papillary muscles or chordae. $J$ Thorac Cardiovasc Surg. 2004;127:481-9.

6. Deb SJ, Schaff HV, Dearani JA, Nishimura RA, Ommen SR. Septal myectomy results in regression of left ventricular hypertrophy in patients with hypertrophic obstructive cardiomyopathy. Ann Thorac Surg. 2004;78:2118-22.

7. Dearani JA, Danielson GK. Septal myectomy for obstructive hypertrophic cardiomyopathy. Semin Thorac Cardiovasc Surg Pediatr Card Surg Аnпи. 2005:86-91.

8. Ommen SR, Maron BJ, Olivotto I, Maron MS, Cecchi F, Betocchi S, et al. Long-term effects of surgical septal myectomy on survival in patients with obstructive hypertrophic cardiomyopathy. J Am Coll Cardiol. 2005;46:470-6.

9. Nicks R, Cartmill T, Bernstein L. Hypoplasia of the aortic root. The problem of aortic valve replacement. Thorax. 1970;25:339-46.

10. Manouguian S, Seybold-Epting W. Patch enlargement of the aortic valve ring by extending the aortic incision into the anterior mitral leaflet. New operative technique. J Thorac Cardiovasc Surg. 1979;78: 402-12.

11. Keane JF, Fellows KE, LaFarge CG, Nadas AS, Bernhard WF. The surgical management of discrete and diffuse supravalvar aortic stenosis. Circulation. 1976;54:112-7.

12. Harikrishnan S, Manohar SR, Nair KK, Tharakan J, Titus T, Kumar VK, et al. Supravalvar aortic stenosis: clinical and hemodynamic profile, and surgical outcome. Indian Heart J. 2003;55:49-54.

13. Chard RB, Cartmill TB. Localized supravalvar aortic stenosis: a new technique for repair. Ann Thorac Surg. 1993;55:782-4.

14. Sharma BK, Fujiwara H, Hallman GL, Ott DA, Reul GJ, Cooley DA. Supravalvar aortic stenosis: a 29-year review of surgical experience. Ann Thorac Surg. 1991;51:1031-9.

15. Konno S, Imai Y, Iida Y. A new method for prosthetic valve replacement in congenital aortic stenosis associated with hypoplasia of the aortic valve ring. J Thorac Cardiovasc Surg. 1975;70:909-17.

16. Rastan H, Koncz J. Aortoventriculoplasty: a new technique for the treatment of left ventricular outflow tract obstruction. J Thorac Cardiovasc Surg. 1976;71:920-7.

17. Cobanoglu A, Thyagarajan GK, Dobbs J. Konno-aortoventriculoplasty with mechanical prosthesis in dealing with small aortic root: a good surgical option. Eur J Cardiothoracic Surg. 1997;12:766-770.

18. De Vivie ER, Borowski A, Mehlhorn U. Reduction of the leftventricular outflow-tract obstruction by aortoventriculoplasty-longterm results of 96 patients. Thorac Cardiovasc Surg. 1993;41:216-23.

19. Fleming WH, Sarafian LB. Aortic valve replacement with concomitant aortoventriculoplasty in children and young adults: long-term follow-up. Ann Thorac Surg. 1987;43:575-8.

20. Misbach GA, Turley K, Ullyot DJ, Ebert PA. Left ventricular outflow enlargement by the Konno procedure. J Thorac Cardiovasc Surg. 1982;84:696-703.

21. Ullmann MV, Gorenflo M, Sebening C, Lange R, Jakob HG, Ulmer HE, et al. Long-term results after reconstruction of the left ventricular outflow tract by aortoventriculoplasty. Ann Thorac Surg. 2003;75: 143-6.

22. Wojtalik M, Sharma GK, Siwinska A, Szelagowicz B, Henschke J. Aortic valve replacement with aortoventriculoplasty in young patients. Cor Europaeum Eur J Cardiac Intervent. 2000;8:150-3.

23. Calhoon JH, Bolton JW. Ross/Konno procedure for critical aortic stenosis in infancy. Ann Thorac Surg. 1995;60(6 Suppl):S597-9. 
24. Erez E, Kanter KR, Tam VK, Williams WH. Konno aortoventriculoplasty in children and adolescents: from prosthetic valves to the Ross operation. Ann Thorac Surg. 2002;74:122-6.

25. Lacour-Gayet F, Sauer H, Ntalakoura K, Muller A, Razek V, Weil J, et al. Ross-Konno procedure in neonates: report of three patients. Ann Thorac Surg. 2004;77:2223-5.

26. Erez E, Tam VK, Doublin NA, Stakes J. Repeat right ventricular outflow tract reconstruction using the Medtronic Freestyle porcine aortic root. J Heart Valve Dis. 2006;15:92-6.

27. Reddy VM, Rajasinghe HA, Teitel DF, Haas GS, Hanley FL. Aortoventriculoplasty with the pulmonary autograft: the "Ross-Konno" procedure. J Thorac Cardiovasc Surg. 1996;111:158-67.

28. Erez E, Tam VK, Williams WH, Kanter KR. The Konno aortoventriculoplasty for repeat aortic valve replacement. Eur J Cardiothoracic Surg. 2001;19:793-6.

29. Tomik A, Wojtalik M, Wróblewska-Kalizewska M, Werner B. Konno procedure and prosthetic valve replacement for aortic insufficiency in an 11-month-old baby. Ped Pol. 1998;2:147-9.

30. McIntyre B, Guyton RA, Jones EL. Reoperation for prosthetic valve degeneration after Konno aortoventriculoplasty. J Thorac Cardiovasc Surg. 1986;91:934-6.

31. Ohye RG, Gomez CA, Ohye BJ, Goldberg CS, Bove EL. The Ross/ Konno procedure in neonates and infants: intermediate-term survival and autograft function. Ann Thorac Surg. 2001;72:823-30.

32. Sharma GK, Wojtalik M, Siwinska A, Mrozinski B, Pawelec-Wojtalik M, Bartkowski R. Aortoventriculoplasty and left ventricle function: Long-term follow-up. Eur J Cardiothoracic Surg. 2004;26:29-136.

33. Kirsch EW, Radu NC, Mekontso-Dessap A, Hillion ML, Loisance D. Aortic root replacement after previous surgical intervention on the aortic valve, aortic root, or ascending aorta. The $J$ Thorac Cardiovasc Surg. 2006;131:601-8.

\section{Discussion}

Dr Thomas L. Spray (Philadelphia, Pa). I congratulate Puga and associates for a very large series of the Konno operation, which is a rare procedure in most centers. The midterm follow-up seems to be, I would say midterm rather than long-term, an average of about 6 years. I have several questions for Dr Puga.

First, the indications for the operative procedure were divided into three different groups, subaortic tunnel stenosis, multilevel LVOTO, and aortic valve stenosis and hypoplasia, but there is often significant overlap in these particular categories. It is not uncommon for patients to have subaortic, annular, valvular, and supravalvular aortic obstruction, and it is not clear to me how you then categorized these patients into these different subgroups. For example, multilevel LVOTO may be equivalent to subaortic tunnel stenosis, and it is often associated with aortic hypoplasia and valve disease. So could you be more clear about how you categorized each of the patients preoperatively? Were the patients who had multilevel LVOTO, for example, really patients that had levels of subaortic stenosis that might be treated with a modified Konno operation, and how did you decide whether to do a valve replacement procedure like the Konno as opposed to a modified Konno operation? You noted that a lot of these patients had aortic regurgitation. So was aortic regurgitation actually the indication for doing a more complex operation with a valve replacement?

A second question regards a surprising finding of your study, the relatively high risk of aortic reoperation at $3.9 \%$ per year. About $70 \%$ of the patients had a mechanical valve prosthesis implanted, and aortic stenosis was the cause of about $40 \%$, if I calculated it right, of the reoperations. You noted that the operative indication of annular hypoplasia with aortic stenosis was a risk factor for reoperation, and that came out in your multivariate analysis. I noted in the manuscript that prosthesis size actually approached but did not quite reach significance as a risk factor for reoperation. So is the potential reason for the reoperation rate being so high the fact that patients with annular hypoplasia perhaps didn't have a large enough patch put in the ventricular septum? You suggest that patients with tunnel subaortic stenosis have a decreased risk of reoperation, potentially related to the large septal patch, which would tend to confirm that the septal patch may have a lot to do with this, and maybe you are undersizing the annulus at the time of implantation. Were there other patients, for example, who had minimal or no septal patches placed?

Also please comment, in relation to this finding that the aortic valve prosthesis may be somewhat small, whether those patients should really be considered for the Ross-Konno operation with a root replacement. How do you now decide whether to do a RossKonno versus an actual Konno operation with a mechanical prosthesis?

Third, the PR you saw seemed to be relatively early, although there was a late hazard phase. Was there any attempt made to correlate the operative technique or the findings in the operating room with the development of late PR? For example, was there any evidence of pulmonary valve injury or valve dysfunction in the operating room or early at discharge that might suggest that this was actually an operative damage problem, as opposed to a geometry change with time that might lead to regurgitation?

Finally, you noted that there was a small decrease in the ejection fraction early after operation, which then recovered with time, but I noted in the manuscript that the end-diastolic and end-systolic dimensions didn't change before and after surgery, which was somewhat surprising. If those don't change, I can't see how ejection fraction changed. In addition, if many of these patients had significant aortic regurgitation, one would expect to see some change in dimension and, potentially, ejection fraction with time. So I wonder whether you had any evidence of regional wall motion abnormality, for example in the septum, that might have changed or improved through the duration of the study?

I thank you for the opportunity to discuss what I think is an outstanding clinical series.

Dr Puga. My gratitude to Dr Spray for his willingness to review the manuscript in the early stages and for his questions and comments.

In response to your first question, the classification refers to the predominant area of obstruction in the left ventricular outflow tract at the time of the Konno operation. Inevitably, these groups overlap because of the complexity of the pathologic changes. Indeed, patients may have had preliminary interventions to resolve specific problems and may have ended with the Konno operation as the final solution to the problems affecting the left ventricular outflow tract. As you suggest, some patients underwent preliminary resection of subaortic stenosis, which may have resulted in inadequate relief or recurrence of the obstruction. Or patients may have had a modified Konno procedure with adequate relief of the subaortic obstruction but with newly appearing aortic valve stenosis or insufficiency. Either of these scenarios in a growing child requires the Konno procedure to allow the insertion of an adultsized valvular prosthesis.

In response to your second question, I must accept that there was a relatively high incidence of reoperation because of aortic stenosis. This reflects our inability to insert in a small growing 
child a prosthesis that would approximate a satisfactory adult size (21 mm or larger). With the smaller prosthesis, patient-prosthesis mismatch will inevitably develop, resulting in aortic stenosis even in the presence of a normally functioning valve. As you suggest, we are indeed undersizing the area of implantation of the prosthesis and patch necessary to complete the Konno procedure. I find this one of the strongest limitations of the Konno operation in a growing child, a limitation that has encouraged us to use the Ross-Konno procedure in patients in whom we are unable to implant a valve $21 \mathrm{~mm}$ or larger.

In response to your third question, there was indeed a correlation between injury to the pulmonary valve at the time of the Konno operation and the need for late reintervention for pulmonary valve insufficiency. I believe that the pulmonary valve is quite exposed to injury during the procedure because of the very limited space between the right coronary ostia and the lateral commissure of the aortic valve. In an effort to avoid injury to the coronary ostia, the surgeon places his annular transecting incision as close to the commissure as possible. Again, this is a specific problem of the Konno operation.

Your fourth question refers to changes in left ventricular ejection fraction seen after the Konno procedure. I believe this might be the effect of early paradoxic movement of the patch, which may improve with time as the patch stiffens. We have seen this in patients undergoing the Rastelli procedure, in whom a similarly placed patch can cause the same phenomenon.

Dr Hillel Laks (Los Angeles, Calif). I enjoyed this presentation very much, and I just wanted to ask you about the failure of the prosthetic aortic valves. What we have seen in younger children and adolescents, possibly because of their ability to create pseudo- intima much more than adults, is that although we are talking to their families about a potential curative operation with a permanent valve, in fact a very big percentage, even with adequately sized valves for their body size, are coming back with a pannus below the valve, which is part of the obstruction, and I wondered whether you had seen that and whether it wasn't altogether a body mismatch but also some pannus embedded in the Konno because of the proximity to the Dacron polyester fabric graft, whether that perhaps exaggerates the pannus ingrowth?

Dr Puga. Yes, indeed, we have seen in many of these reoperations an excessive amount of scarring at the point of implantation to the septum and under the valve. Pannus formation is particularly likely to cause problems in patients who bear small prostheses.

Dr Richard A. Jonas (Washington, DC). I agree that if you do an aggressive enlargement with a Konno procedure anteriorly that you run a risk that you are either going to impinge on the pulmonary valve or the right coronary. What about the option of combining an anterior enlargement with a Konno and a posterior enlargement with a Manouguian, which seems to me to be more symmetrical? We have been moving toward using more combined ManouguianKonno type procedures rather than an ultra-aggressive Konno procedure.

Dr Puga. I would agree with that. I have done a procedure in which a Konno was done with a miniroot autograft, implanting both coronaries and enlarging the site of implantation both posteriorly and anteriorly. That indeed may be another option for the procedure to avoid having to enlarge the outflow tract anteriorly so extensively. 
TABLE E1. Indications for operation

\begin{tabular}{lcc}
\hline Indication & No. & $\%$ \\
\hline Multilevel LVOTO & 23 & 43 \\
Tunnel subaortic stenosis & 18 & 34 \\
AS, AR, hypoplasia & 12 & 23
\end{tabular}

LVOTO, Left ventricular outflow tract obstruction; $A S$, aortic stenosis; $A R$, aortic regurgitation
TABLE E2. Konno operation

\begin{tabular}{|c|c|c|}
\hline Component & No. & $\%$ \\
\hline \multicolumn{3}{|l|}{ Valve } \\
\hline Mechanical & 40 & 75 \\
\hline Homograft & 10 & 19 \\
\hline Xenograft & 3 & 6 \\
\hline \multicolumn{3}{|l|}{ Septal patch } \\
\hline Dacron & 30 & 57 \\
\hline Meadox & 7 & 13 \\
\hline Homograft & 7 & 13 \\
\hline Pericardium & 4 & 8 \\
\hline Tascon & 4 & 8 \\
\hline Gore-Tex & 1 & 2 \\
\hline \multicolumn{3}{|l|}{ Right ventricular patch } \\
\hline Pericardium & 39 & 74 \\
\hline Dacron & 4 & 8 \\
\hline Meadox & 4 & 8 \\
\hline Tascon & 3 & 6 \\
\hline Homograft & 2 & 4 \\
\hline Primary closure & 1 & 2 \\
\hline \multicolumn{3}{|l|}{ Other } \\
\hline MVR & 4 & 8 \\
\hline MV repair & 3 & 6 \\
\hline TV repair & 2 & 4 \\
\hline VSD closure & 2 & 4 \\
\hline CABG & 2 & 4 \\
\hline Permanent pacemaker & 1 & 2 \\
\hline Bypass (min, median and range) & $173(75-327)$ & \\
\hline Crossclamp (min, median and range) & $114(54-234)$ & \\
\hline \multicolumn{3}{|l|}{ Nonfatal complications } \\
\hline Heart block & 6 & 11 \\
\hline Sepsis & 2 & 4 \\
\hline Bleeding & 1 & 2 \\
\hline Respiratory failure & 1 & 2 \\
\hline Renal failure & 1 & 2 \\
\hline
\end{tabular}

$M V R$, Mitral valve replacement; $M V$, mitral valve; $T V$, tricuspid valve; $V S D$, ventricular septal defect; $C A B G$, coronary artery bypass grafting. 
TABLE E3. Indications for reoperation

\begin{tabular}{llr}
\hline Indication & No. & $\%$ \\
\hline Aortic & & \\
$\quad$ Valve stenosis & 6 & 11 \\
$\quad$ Valve regurgitation & 5 & 9 \\
$\quad$ Endocarditis & 3 & 6 \\
Other & & \\
VSD & 3 & 6 \\
Pulmonary valve replacement & 3 & 6 \\
Mitral valve replacement & 2 & 4 \\
Tricuspid valve replacement & 2 & 4 \\
Heart transplant & 1 & 2
\end{tabular}

VSD, Ventricular septal defect. 